\title{
Identifying Persons with Axial Spondyloarthritis At Risk of Poor Work Outcome: Results from the British Society for Rheumatology Biologics Register
}

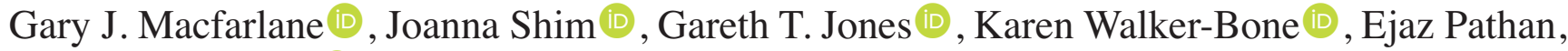 \\ and Linda E. Dean 1
}

ABSTRACT. Objective. First, to test the hypothesis that, among working patients with axial spondyloarthritis $(\operatorname{axSpA})$, those who report issues with reduced productivity at work (presenteeism) are at higher risk of work absence (absenteeism), and patients who report absenteeism are at higher risk of subsequently leaving the workforce. Second, to identify characteristics of workers at high risk of poor work outcome.

Methods. The British Society for Rheumatology Biologics Register in Ankylosing Spondylitis has recruited patients meeting Assessment of Spondyloarthritis international Society criteria for axSpA from 83 centers. Data collection involved clinical and patient-reported measures at recruitment and annually thereafter, including the Work Productivity and Activity Impairment scale. Generalized estimating equations were used to identify factors associated with poor work outcomes.

Results. Of the 1188 participants in this analysis who were working at recruitment, $79 \%$ reported some presenteeism and $19 \%$ some absenteeism in the past week owing to their axSpA. Leaving employment was most strongly associated with previous absenteeism (RR 1.02 per \% increase in absenteeism, 95\% CI 1.01-1.03), which itself was most strongly associated with previous presenteeism, a labor-intensive job, and peripheral joint involvement. High disease activity, fatigue, a labor-intensive job, and poorer physical function were all independently associated with future presenteeism.

Conclusion. Clinical and patient-reported factors along with aspects of work are associated with an increased risk of axSpA patients having a poor outcome in relation to work. This study has identified modifiable factors as targets, facilitating patients with axSpA to remain productive at work. (First Release November 1 2018; J Rheumatol 2019;46:145-52; doi:10.3899/jrheum.180477)

Key Indexing Terms:

\begin{tabular}{|c|c|}
\hline SPONDYLOARTHRITIS & WORK \\
\hline
\end{tabular}

From the Epidemiology Group, School of Medicine, Medical Sciences and Nutrition, and the Aberdeen Centre for Arthritis and Musculoskeletal Health, and the Medical Research Council (MRC)/Arthritis Research UK Centre for Musculoskeletal Health and Work, University of Aberdeen, Aberdeen, UK; MRC Lifecourse Epidemiology Unit, University of Southampton, Southampton, UK; Spondylitis Program, Department of Rheumatology, Toronto Western Hospital, University Health Network, Toronto, Ontario, Canada.

Research funding from the MRC/Arthritis Research UK Centre for Musculoskeletal Health and Work (grant no: 20665 CI KW-B). The British Society for Rheumatology Biologics Register in Ankylosing Spondylitis (BSRBR-AS) is funded by the BSR, which received funding for this research from Pfizer, AbbVie, and UCB. These companies received advance copies of manuscripts for comments. They had no input in determining the topics for analysis or the work involved in undertaking it. G.J. Macfarlane, MD, Dean of Research and Knowledge Exchange (Life Sciences and Medicine) and Chair in Epidemiology, Epidemiology Group, School of Medicine, Medical Sciences and Nutrition, and Aberdeen Centre for Arthritis and Musculoskeletal Health, and MRC/Arthritis Research UK Centre for Musculoskeletal Health and Work, University of Aberdeen; J. Shim, PhD, Research Fellow (Epidemiology), Epidemiology Group, School of Medicine, Medical Sciences and Nutrition, and Aberdeen Centre for Arthritis and Musculoskeletal Health, and MRC/Arthritis Research UK Centre for Musculoskeletal Health and Work, University of Aberdeen; G.T. Jones, PhD, Reader of Epidemiology, Epidemiology Group, School of Medicine, Medical Sciences and Nutrition, and Aberdeen Centre for
Arthritis and Musculoskeletal Health, and MRC/Arthritis Research UK Centre for Musculoskeletal Health and Work, University of Aberdeen; K. Walker-Bone, PhD, Professor of Occupational Rheumatology, MRC/Arthritis Research UK Centre for Musculoskeletal Health and Work, and MRC Lifecourse Epidemiology Unit, University of Southampton; E. Pathan, PhD, Research Fellow (Rheumatology), Spondylitis Program, Department of Rheumatology, Toronto Western Hospital, University Health Network; L.E. Dean, PhD, Research Assistant, Epidemiology Group, School of Medicine, Medical Sciences and Nutrition, and Aberdeen Centre for Arthritis and Musculoskeletal Health, and MRC/Arthritis Research UK Centre for Musculoskeletal Health and Work, University of Aberdeen.

Address correspondence to Prof. G.J. Macfarlane, School of Medicine, Medical Sciences and Nutrition, University of Aberdeen, Health Sciences Building (1st floor), Foresterhill, Aberdeen AB25 2ZD, UK.

E-mail: g.j.macfarlane@abdn.ac.uk

Full Release Article. For details see Reprints and Permissions at jrheum.org

Accepted for publication August 8, 2018.

Axial spondyloarthritis (axSpA) has been demonstrated to affect the work of patients. The effect includes, at its most extreme, the necessity to stop working or to change jobs to one more suited to limitations imposed on the patient by the

Personal non-commercial use only. The Journal of Rheumatology Copyright (c) 2019. All rights reserved. 
condition. Another important effect is that which having axSpA has on being able to perform one's job (presenteeism) ${ }^{1}$. In a study of 301 patients with axSpA in a single center in the United Kingdom that used the Work Productivity and Activity Impairment scale to measure the effect on work, mean levels of absenteeism due to axSpA were $5 \%$ but $22 \%$ for presenteeism ${ }^{2}$, while similar data (absenteeism 9\%, presenteeism 33\%) were provided from an analysis of 105 patients in the SPondyloArthritis Caught Early (SPACE) study involving 4 centers in the Netherlands, Norway, and Italy ${ }^{3}$.

Patients consider that work should be a priority for research studies. The National Ankylosing Spondylitis Society (NASS), the patient organization in the UK that represents and supports people with ankylosing spondylitis (AS), carried out a formal project in 2013 to understand the key priorities for patients in terms of research. All members were invited to respond to the question, "What kinds of issues need to be understood better to make living with and managing AS easier?" Responses from 150 members were fed into a subsequent priority-setting exercise using a World Café format ${ }^{4}$ involving rheumatologists, clinicians, and allied health professionals. Among lifestyle factors, the top research priority identified was to "understand the impact of AS on employment and how people maintain employment and develop their careers while managing their AS" (nass.co.uk/nass/en/research).

It has been noted that "even more than today, work will become as much a social act as an economic one. It will help define us as individuals, provide social networks, support, community and ... connection to a wider purpose." 5 This emphasizes the wider importance of enabling patients with axSpa and other chronic conditions to remain in the workplace. A key issue in doing so is to understand the pathway leading to a poor work outcome, allowing the identification of a group of "high-risk" patients. First, we propose to test the hypothesis that working patients with axSpA who report issues with work productivity are at higher risk of work absence, and patients who report work absence are at higher risk of subsequently leaving the workforce. If the model is supported, we will identify characteristics of patients at risk of poor work outcome.

\section{MATERIALS AND METHODS}

The British Society for Rheumatology Biologics Register in Ankylosing Spondylitis (BSRBR-AS) is a prospective cohort study, involving 83 centers throughout Great Britain, recruiting patients meeting Assessment of Spondyloarthritis international Society (ASAS) criteria for axSpA ${ }^{6}$ and who were naive to biologic therapy. Recruitment took place December 2012-December 2017, initially for patients meeting the ASAS imaging criteria for axSpA. Patients who met only the ASAS clinical criteria were subsequently eligible to be recruited from November 2014. There are 2 subcohorts: those about to commence a biologic agent (biologic cohort) and those continuing on other therapy (nonbiologic cohort). Eligible therapies were adalimumab, etanercept, and certolizumab pegol. The full study protocol has been published previously ${ }^{7}$. Participants were required to be aged at least 16 years and be naive to biologic therapy at the time of recruitment. All participants gave informed consent. The biologic cohort was followed up at 3 months and 6 months, and both cohorts were followed up at 12 months and yearly thereafter, up to a maximum of 5 years. If a patient in the nonbiologic cohort commenced biologic therapy, he or she switched cohort and began a new followup schedule. At each followup, in addition to clinical data obtained during rheumatology appointments, patient-reported questionnaires were completed.

The primary outcome of interest for the current analysis was poor work outcome, as assessed by the Work Productivity and Activity Impairment Specific Health Problem v2.0 (WPAI:SHP) scale ${ }^{8}$. This instrument determines work status and then, among those working, evaluates the effect of disease on work and other daily activities over the previous 7 days. The outcomes generated include a measure of the proportion of work time missed (absenteeism), impairment while at work (presenteeism), overall work impairment (combination of absenteeism and presenteeism), and proportion of impairment in other activities. This instrument has been validated for use with AS patients ${ }^{9}$. In relation to their job, respondents were also asked whether it was mainly desk-based/sedentary or physical/labor-intensive.

Measures at recruitment (baseline) and at each followup timepoint, used in the current analysis as explanatory variables, include clinical data: the use of biologic therapy (yes/no), presence of extraspinal manifestations (history of uveitis, psoriasis, inflammatory bowel disease, peripheral joint involvement, and dactylitis) and the Bath AS Metrology Index [BASMI; scored 0 (least)-10 (most) severe ${ }^{10}$. Patient-reported measures of health included several Bath AS indices: Disease Activity Index (BASDAI), Functional Index (BASFI), and Global health [BAS-G; all scored from 0 (least) to 10 (most) severe] ${ }^{11,12,13}$. Quality of life was evaluated through the AS Quality of Life score [ASQoL; scored 0 (good)-18 (poor)] ${ }^{14}$, overall health by the European Quality of Life visual analog scale [EQ-VAS; scored 0 (worst imaginable health)-100 (best imaginable) $]^{15}$, and mental health using the Hospital Anxiety and Depression Scale (grouped into none, borderline, and clinical through standard cutoffs) ${ }^{16}$. Spinal pain was assessed using a 10-cm VAS, fatigue through the Chalder Fatigue Scale [scored 0 (best)-11 (worst) $]^{17}$, and sleep disturbance by the Jenkins Sleep Evaluation Questionnaire [JSEQ; scored 0 (no sleep problems)-20 (poor sleep)] ${ }^{18}$

A measure of socioeconomic status, the Index of Multiple Deprivation, was derived from the residence postcode of participants, categorized into quintiles [0 (least deprived) -4 (most deprived)] with reference to their country of residence ${ }^{19,20}$

The BSRBR-AS received ethical approval from the National Research Ethics Service Committee North East - County Durham and Tees Valley (REC ref 11/NE/0374).

Statistical analysis. For the purpose of our current study, data collected at baseline and all followups were used and the analysis uses the June 2017 version of the study database.

Differences in the characteristics of those working and not working at baseline were assessed using simple descriptive statistics, including initial absenteeism, presenteeism, and overall work impairment scores. The baseline likelihood of working was further assessed using logistic regression models, adjusted for age, sex, and deprivation

To test the initial hypothesis, 3 separate analyses were conducted to determine the factors associated with (1) leaving work, (2) absenteeism, and (3) presenteeism, at 12-month followup intervals. Participants were categorized as having left work if they were not working at a followup assessment but had been working 12 months prior, and they were of normal working age (females $<60$ yrs and males $<65 \mathrm{yrs}$ ). Factors associated with work withdrawal were explored using generalized estimating equation (GEE) models ${ }^{21}$. GEE takes into account withinsubject correlations, thus allowing the analysis of multiple observations from the same individual across multiple timepoints. Thus, baseline information was related to work outcome at 12 months, 12-month information was related to work outcome at 24 months, and so on. The log-link function was used (fitting a Poisson model) as appropriate, with an independent correlation matrix, including a robust variance estimator ${ }^{22}$.

Personal non-commercial use only. The Journal of Rheumatology Copyright $\odot$ (2019. All rights reserved 
All models were adjusted for age, sex, and deprivation, and presented as risk ratios (RR) or coefficients with $95 \% \mathrm{CI}$.

Factors related to (1) leaving work, (2) absenteeism, and (3) presenteeism were assessed initially by GEE regression models as outlined above. Those factors reaching a significance threshold of $\mathrm{p} \leq 0.20$ were offered to a forward stepwise regression process (linear GEE or Poisson GEE as appropriate) to determine which group of factors produced the best-fitting models for the outcomes of leaving work, presenteeism, and absenteeism. Factors entered the model at $\mathrm{p} \leq 0.10$ and exited at $\mathrm{p} \geq 0.15$ with adjustment for age, sex, deprivation, and relevant baseline measures (absenteeism or presenteeism as applicable).

All analyses were conducted using Stata (StataCorp LP version 15.0).

\section{RESULTS}

At baseline, 1921 participants returned a questionnaire and provided information on work status. Of these, $62 \%$ $(n=1188)$ reported they were currently in paid employment and these represent the study population for the current analysis: $65 \%$ were male, with a median age of 44 years [interquartile range (IQR) 35-52 yrs], 55\% worked in a sedentary job, $83 \%$ of those tested were HLA-B27+, and the median age of referral to a rheumatologist with symptoms was 33 years (IQR 26-42 yrs). The likelihood of working decreased (after adjustment for age, sex, and deprivation) with higher disease activity (OR 0.74 per unit increase in BASDAI, 95\% CI 0.70-0.79), poorer physical function
(BASFI 0.70/unit increase, 95\% CI 0.66-0.73), poorer spinal mobility (BASMI 0.69/unit increase (95\% CI 0.64-0.75), and worse quality of life (ASQoL 0.84/unit increase, 95\% CI $0.81-0.86$; Table 1). A higher proportion of those not working fulfilled the modified New York criteria for AS, compared to those working (15\% vs 7\%). Among working participants, $79 \%$ reported some presenteeism owing to their axSpa during the past week (median 30\%, IQR 10-50\%), while 19\% reported some absenteeism (median 0\%,0-0\%).

Factors associated with leaving work during followup. The 1188 participants working at baseline provided a total of 962 annual periods of observation (i.e., 12-month periods in which both exposure and outcome information was available) when they were still of normal working age (based on sex). In total, 52 persons reported leaving work during followup while still of working age.

In the GEE analysis, using all followup timepoints and adjusting for age, sex, and deprivation, absenteeism was the only significant factor related to leaving work 12 months later (RR 1.02 per percent increase in absenteeism, 95\% CI 1.01-1.03; Table 2). There were no statistically significant or important differences between those who remained and did not remain at work regarding whether they were receiving biologic therapy, anxiety or depression, Bath indices, quality

Table 1. Baseline characteristics of the BSRBR-AS population.

\begin{tabular}{|c|c|c|}
\hline Characteristics & Working, $\mathrm{n}=1188$ & Not Working, $\mathrm{n}=733$ \\
\hline Age, yrs $* *$ & $43.7(34.6-52.3)$ & $62.2(48.1-68.3)$ \\
\hline Age at rheumatology referral, yrs $* *$ & $33(26-42)$ & $41(29-52)$ \\
\hline Sex, male* & $767(65)$ & $529(72)$ \\
\hline \multicolumn{3}{|l|}{ Classification criteria** } \\
\hline ASAS clinical & $635(53)$ & $237(32)$ \\
\hline ASAS imaging & $475(40)$ & $383(52)$ \\
\hline Modified New York criteria & $78(7)$ & $113(15)$ \\
\hline \multicolumn{3}{|l|}{ HLA-B27 status** } \\
\hline Positive & $684(83)$ & $337(75)$ \\
\hline Negative & $145(17)$ & $115(25)$ \\
\hline \multicolumn{3}{|l|}{ Job type } \\
\hline Sedentary & $715(55)$ & - \\
\hline Labor-intensive & $592(45)$ & - \\
\hline Absenteeism, \% & $0(0-0)$ & - \\
\hline Presenteeism, \% & $30(10-50)$ & - \\
\hline Overall work impairment, $\%$ & $30(10-53)$ & - \\
\hline \multirow{2}{*}{ Activity impairment, $\% * *$} & $30(10-60)$ & $60(30-80)$ \\
\hline & \multicolumn{2}{|c|}{ Logistic Regression $^{\dagger}$} \\
\hline Likelihood of working ${ }^{* *}$ & $\mathrm{OR}$ & $95 \% \mathrm{CI}$ \\
\hline BASDAI (scored: 0 best-10 worst) & 0.74 & $0.70-0.79$ \\
\hline BASFI (scored: 0 best-10 worst) & 0.70 & $0.66-0.73$ \\
\hline BASMI (scored: 0 best-10 worst) & 0.69 & $0.64-0.75$ \\
\hline ASQoL (scored: 0 best-18 poorest) & 0.84 & $0.81-0.86$ \\
\hline
\end{tabular}

Values are $\mathrm{n}(\%)$ or median (IQR) unless otherwise indicated. * Statistically significant difference between work and not working of $\mathrm{p}<0.05$. ** Statistically significant difference between work and not working of $\mathrm{p}<0.01$. $\dagger$ Adjusted for age, sex, and deprivation. BSRBR-AS: British Society for Rheumatology Biologics Register in Ankylosing Spondylitis; ASAS: Assessment of Spondyloarthritis international Society; BASDAI: Bath Ankylosing Spondylitis Disease Activity Index; BASFI: Bath AS Functional Index; BASMI: Bath AS Metrology Index; ASQoL: Ankylosing Spondylitis Quality of Life questionnaire; IQR: interquartile range. 
Table 2. Factors associated with no longer working 12 months later.

\begin{tabular}{llcc}
\hline \multirow{2}{*}{ Baseline Factors } & \multicolumn{2}{c}{ GEE Poisson Regression } \\
& & RR & 95\% CI \\
\hline \multirow{2}{*}{ Work } & Job type (labor-intensive vs sedentary) & 1.4 & $(0.8-2.5)$ \\
& Absenteeism, \%* & 1.02 & $(1.01-1.03)$ \\
& Presenteeism, \% & 1.0003 & $(0.99-1.01)$ \\
& Commencing biologic (yes vs no) & 1.01 & $(0.5-2.3)$ \\
& Uveitis (yes vs no) & 0.5 & $(0.2-1.3)$ \\
& Psoriasis (yes vs no) & 1.2 & $(0.5-3.1)$ \\
& Inflammatory bowel disease (yes vs no) & 0.99 & $(0.3-2.8)$ \\
& Dactylitis (yes vs no) & & low no. observations \\
& Peripheral joint involvement (yes vs no) & & low no. observations \\
& BASDAI (score 0-10) & 0.96 & $(0.8-1.1)$ \\
& BASFI (score 0-10) & 1.02 & $(0.9-1.1)$ \\
& BASMI (score 0-10) & 1.1 & $(0.9-1.5)$ \\
& BAS-G (score 0-10) & 1.1 & $(0.9-1.2)$ \\
Patient & ASQoL (score 0-18) & 1.03 & $(0.98-1.1)$ \\
& EQ-VAS (score 0-100) & 0.99 & $(0.99-1.02)$ \\
& Activity impairment, \% & 1.01 & $(0.9-1.1)$ \\
& Spinal pain (score 0-10) & 1.001 & $(0.9-1.1)$ \\
& Chalder Fatigue Scale (score 0-11) & 0.97 & $(0.95-1.04)$ \\
& Sleep disturbance (score 0-20) & 0.99 & $(0.6-1.8)$ \\
& HADS Anxiety (clinical/borderline vs none) & 1.04 & $(0.8-2.7)$ \\
\hline
\end{tabular}

\footnotetext{
$\dagger$ Adjusted for age, sex, and deprivation. * Statistically significant difference between those working and no longer working of $\mathrm{p}<0.01$. GEE: generalized estimating equation; BASDAI: Bath Ankylosing Spondylitis Disease Activity Index; BASFI: Bath AS Functional Index; BASMI: Bath AS Metrology Index; BAS-G: Bath AS Global score; ASQoL: AS Quality of Life questionnaire; EQ-VAS: EuroQol visual analog scale; HADS: Hospital Anxiety and Depression Scale.
}

of life, activity impairment, spinal pain, fatigue, or sleep disturbance. Neither were there significant differences in presenteeism or whether they worked in a manual or sedentary job. A further stepwise model was therefore not necessary. The relationships between peripheral joint involvement or the presence of dactylitis with work withdrawal were not assessed, because of the low number of such persons ( 1 and 0 persons, respectively).

Factors associated with future absenteeism. Using all followup timepoints, adjusted for age, sex, and deprivation, the GEE models indicated that several factors were significantly associated with absenteeism 12 months later (Table 3 ). These included work factors [presenteeism: $0.14 \%$ average increase in absenteeism at followup for every $\%$ increase in presenteeism at baseline (95\% CI 0.07-0.2)], a labor-intensive job $(2.7,95 \%$ CI 0.4-4.9), Bath indices (BASDAI 1.2, 95\% CI 0.7-1.8; BASFI 0.9, 95\% CI 0.4-1.4; BAS-G 1.1, 95\% CI 0.6-1.6), quality of life (ASQoL 0.5, 95\% CI $0.3-0.8)$, activity impairment $(0.13,95 \%$ CI $0.08-0.2)$, spinal pain $(1.01,95 \%$ CI $0.5-1.5)$, fatigue (Chalder $0.4,95 \%$ CI $0.02-0.8$ ), and sleep disturbance (JSEQ 0.4, 95\% CI 0.2-0.6). Although eligible for the stepwise model, both activity impairment and presenteeism were highly correlated (correlation 0.8). During the stepwise process, both factors fought for entry and a model solution could not be reached. Because it was not possible to offer both factors to the model, presen- teeism was chosen; it showed the strongest relationship to absenteeism during univariate analysis (coefficient 0.14 vs $0.13)$. Of the eligible factors offered to the stepwise model ( $\mathrm{p} \leq 0.20$, with adjustment for age, sex, deprivation, and baseline absenteeism), the only ones that entered the linear regression model (in order) were presenteeism $(0.1,95 \% \mathrm{CI}$ $0.04-0.2)$, a labor-intensive job $(2.3,95 \% \mathrm{CI}-0.4$ to 5.0$)$, and peripheral joint involvement $(4.3,95 \%$ CI -0.4 to 5.0 ; Supplementary Table 1, available with the online version of this article).

Factors associated with future presenteeism. Using all followup timepoints, adjusted for age, sex, and deprivation, the GEE models indicated that several factors were significantly associated with presenteeism 12 months later (Table 4). These factors were associated with greater presenteeism: clinical/borderline anxiety and depression (coefficient 10.7, 95\% CI 7.2-14.2 and 10.0, 95\% CI 5.9-14.1, respectively), higher disease activity, poorer physical function, poorer spinal mobility, and global disease status (BASDAI 4.2, 95\% CI 3.6-4.9; BASFI 3.7, 95\% CI 3.0-4.3; BASMI 1.4, 95\% CI $0.3-2.5$; BAS-G 3.4, 95\% CI 2.8-4.0). Other factors associated with greater presenteeism were poorer quality of life (ASQoL 2.0, 95\% CI 1.7-2.3, EQ-VAS -0.3, 95\% CI -0.4 to -0.2$)$, activity impairment $(0.4,95 \%$ CI $0.3-0.43)$, worse spinal pain $(2.8,95 \%$ CI 2.2-3.4), fatigue (Chalder 2.3, 95\% CI 1.8-2.8), and sleep disturbance (JSEQ $1.1,95 \%$ CI

Personal non-commercial use only. The Journal of Rheumatology Copyright $\subset$ $\subset$ 2019. All rights reserved 
Table 3. Factors associated with absenteeism score 12 months later.

\begin{tabular}{|c|c|c|c|}
\hline \multirow{2}{*}{\multicolumn{2}{|c|}{ Baseline Factors }} & \multicolumn{2}{|c|}{ GEE Linear Regression $^{\dagger}$} \\
\hline & & Coefficient & $95 \% \mathrm{CI}$ \\
\hline \multirow[t]{2}{*}{ Work } & Job type (labor-intensive vs sedentary) & 2.7 & $(0.4-4.9)^{*}$ \\
\hline & Presenteeism, $\%$ & 0.14 & $(0.07-0.2)^{*}$ \\
\hline \multirow[t]{10}{*}{ Clinical } & Commencing biologic (yes vs no) & 2.8 & $(-1.1 \text { to } 6.7)^{*}$ \\
\hline & Uveitis (yes vs no) & -1.4 & $(-4.0$ to 1.1$)$ \\
\hline & Psoriasis (yes vs no) & 2.7 & $(-2.6$ to 8.0$)$ \\
\hline & Inflammatory bowel disease (yes vs no) & 1.1 & $(-4.3$ to 6.4$)$ \\
\hline & Dactylitis (yes vs no) & 3.4 & $(-6.4$ to 13.1$)$ \\
\hline & Peripheral joint involvement (yes vs no) & 3.4 & $(-0.7 \text { to } 7.5)^{*}$ \\
\hline & BASDAI (score 0-10) & 1.2 & $(0.7-1.8)^{*}$ \\
\hline & BASFI (score 0-10) & 0.9 & $(0.4-1.4)^{*}$ \\
\hline & BASMI (score 0-10) & -0.2 & $(-0.9$ to 0.4$)$ \\
\hline & BAS-G (score 0-10) & 1.1 & $(0.6-1.6)^{*}$ \\
\hline \multirow[t]{8}{*}{ Patient } & ASQoL (score 0-18) & 0.5 & $(0.3-0.8)^{*}$ \\
\hline & EQ-VAS (score 0-100) & -0.1 & $(-0.2 \text { to }-0.04)^{*}$ \\
\hline & Activity impairment, $\%$ & 0.13 & $(0.08-0.2)^{*}$ \\
\hline & Spinal pain (score 0-10) & 1.01 & $(0.5-1.5)^{*}$ \\
\hline & Chalder Fatigue Scale (score 0-11) & 0.4 & $(0.02-0.8)^{*}$ \\
\hline & Sleep disturbance (score 0-20) & 0.4 & $(0.2-0.6)^{*}$ \\
\hline & HADS Anxiety (clinical/borderline vs none) & 2.5 & $(0.06-4.9)^{*}$ \\
\hline & HADS Depression (clinical/borderline vs none) & 3.2 & $(0.07-6.4)^{*}$ \\
\hline
\end{tabular}

$\dagger$ Adjusted for age, sex, and deprivation. * Eligible for forward stepwise model ( $\mathrm{p} \leq 0.2)$. GEE: generalized estimating equation; BASDAI: Bath Ankylosing Spondylitis Disease Activity Index; BASFI: Bath AS Functional Index; BASMI: Bath AS Metrology Index; BAS-G: Bath AS Global score; ASQoL: AS Quality of Life questionnaire; EQ-VAS: EuroQol visual analog scale; HADS: Hospital Anxiety and Depression Scale.

Table 4. Factors associated with presenteeism score 12 months later.

\begin{tabular}{|c|c|c|c|}
\hline \multirow{2}{*}{\multicolumn{2}{|c|}{ Baseline Predictors }} & \multicolumn{2}{|c|}{ GEE Linear Regression $^{\dagger}$} \\
\hline & & Coefficient & $95 \% \mathrm{CI}$ \\
\hline \multirow[t]{2}{*}{ Work } & Job type (labor-intensive vs sedentary) & 7.3 & $(3.8-10.7)^{*}$ \\
\hline & Absenteeism, $\%$ & 0.2 & $(0.02-0.3)^{*}$ \\
\hline \multirow[t]{10}{*}{ Clinical } & Commencing biologic (yes vs no) & 6.6 & $(2.1-11.1)^{*}$ \\
\hline & Uveitis (yes vs no) & -0.5 & $(-4.5$ to 3.6$)$ \\
\hline & Psoriasis (yes vs no) & 3.8 & $(-2.6$ to 10.2$)$ \\
\hline & Inflammatory bowel disease (yes vs no) & 1.3 & $(-3.95$ to 6.5$)$ \\
\hline & Dactylitis (yes vs no) & 6.4 & $(-4.9$ to 17.7$)$ \\
\hline & Peripheral joint involvement (yes vs no) & 6.2 & $(1.9-10.6)^{*}$ \\
\hline & BASDAI (score 0-10) & 4.2 & $(3.6-4.9)^{*}$ \\
\hline & BASFI (score 0-10) & 3.7 & $(3.0-4.3)^{*}$ \\
\hline & BASMI (score 0-10) & 1.4 & $(0.3-2.5)^{*}$ \\
\hline & BAS-G (score 0-10) & 3.4 & $(2.8-4.0)^{*}$ \\
\hline \multirow[t]{8}{*}{ Patient } & ASQoL (score 0-18) & 2.0 & $(1.7-2.3)^{*}$ \\
\hline & EQ-VAS (score 0-100) & -0.3 & $(-0.4 \text { to }-0.2)^{*}$ \\
\hline & Activity impairment, $\%$ & 0.4 & $(0.3-0.43)$ \\
\hline & Spinal pain (score $0-10)$ & 2.8 & $(2.2-3.4)^{*}$ \\
\hline & Chalder Fatigue Scale (score 0-11) & 2.3 & $(1.8-2.8)^{*}$ \\
\hline & Sleep disturbance (score 0-20) & 1.1 & $(0.8-1.4)^{*}$ \\
\hline & HADS Anxiety (clinical/borderline vs none) & 10.7 & $(7.2-14.2)^{*}$ \\
\hline & HADS Depression (clinical/borderline vs none) & 10.0 & $(5.9-14.1)^{*}$ \\
\hline
\end{tabular}

\footnotetext{
$\dagger$ Adjusted for age, sex, and deprivation. * Eligible for forward stepwise model ( $p \leq 0.2)$. GEE: generalized estimating equation; BASDAI: Bath Ankylosing Spondylitis Disease Activity Index; BASFI: Bath AS Functional Index; BASMI: Bath AS Metrology Index; BAS-G: Bath AS Global score; ASQoL: AS Quality of Life questionnaire; EQ-VAS: EuroQol visual analog scale; HADS: Hospital Anxiety and Depression Scale.
} 
0.8-1.4). In addition, these were also associated with subsequent presenteeism: commencing biologic therapy (6.6, 95\% CI 2.1-11.1), peripheral joint involvement $(6.2,95 \%$ CI 1.9-10.6), a labor-intensive job (7.3, 95\% CI 3.8-10.7), and greater absenteeism $(0.2,95 \%$ CI $0.02-0.3)$. Of the eligible factors offered to the stepwise linear regression model ( $p \leq 0.20$ ), the only independent factors related to presenteeism at followup, after adjustment for age, sex, deprivation, and baseline presenteeism, were (in order of entry): high disease activity (BASDAI coefficient $0.76,95 \% \mathrm{CI}-0.2$ to 1.8), fatigue (Chalder 0.7, 95\% CI 0.1-1.2), a labor-intensive job $(3.4,95 \%$ CI 0.6-6.1), and poorer physical function (BASFI $0.9,95 \%$ CI -0.03 to 1.8 ; Supplementary Table 2, available with the online version of this article). There were no interactions in this final model that were statistically significant.

\section{DISCUSSION}

This large national prospective cohort study of patients with axSpA has demonstrated that persons of working age who are not in employment have worse disease activity and function, and overall poorer quality of life. One out of 5 patients reported absenteeism in the past week, while 4 out of 5 reported an effect on their ability to undertake tasks while at work. Our proposed pathway to leaving work was supported. It was associated with prior absenteeism, which itself was associated with prior presenteeism and having a labor-intensive job. Disease activity, fatigue, poor function, and a labor-intensive job were the factors most strongly related to future presenteeism.

The strengths of our study include that it is among the largest to examine the effect of axSpA on work and to specifically identify markers of poor work outcome. It has used a validated scale (the WPAI:SHP) to assess the effect on work. However, the scale measures the effect on work over only the past 7 days and in a disease with a fluctuating course and disease flares, such a short period is unlikely to adequately estimate work effect at an individual level. The resulting misclassification of the effect on work (and assuming that this is random) would make it more difficult to identify factors associated with poor work outcome. Developing scales more suited for use in longitudinal studies to record (changes in) the effect on work in conditions such as axSpA should be a priority. Our study recruited patients from more than 80 centers; some were specialist centers for axSpA but most were not. Almost all patients meeting ASAS criteria were eligible to be recruited (only those who had previously started biologic therapy were not eligible), and regarding the recruited population taking biologics, we have shown that they are similar to the axSpA patient population recruited to trials of biologics ${ }^{23}$. Despite the large study population, the number of persons developing the extreme end of a poor work outcome (i.e., leaving employment) is relatively low and therefore this study, as with all studies in this area, has limited power in developing statistical models for this outcome. We have conducted the statistical analysis over 1 -year periods, examining different outcomes and therefore we are studying different patients in relation to each of the outcomes analyzed rather than following patients longitudinally through presenteeism, absenteeism, and job loss. The latter, more methodologically robust approach would require a longterm and very large study of employed patients with axSpA, which is unlikely to be feasible.

There are relatively few data on the effect of specific aspects of work and its influence on axSpA, or indeed the effect of axSpA on the ability to undertake certain jobs. The prospective study DEvenir des Spondyloarthrites Indifférenciées Récentes (DESIR) examined trajectories of disease and factors associated with them. The study noted that white-collar work was associated with the trajectory "persistent inactive" disease ${ }^{24}$. Ramiro, et al ${ }^{25}$ reported in a longitudinal analysis of 136 patients that the relationship between disease activity and radiographic progression was significantly and independently modified by job type. In blue-collar versus white-collar workers, every additional unit of AS Disease Activity Score (ASDAS) resulted in an increase of 1.2 versus 0.2 in the modified Stoke AS Spine Score units per 2 years. These results could be interpreted as supporting the hypothesis that physically demanding jobs increase levels of inflammation. However, they may also reflect confounding. Job category (blue collar vs white collar) is very closely linked to income and socioeconomic status, and also smoking status. The latter specifically has been linked to disease activity and radiographic progression ${ }^{26}$.

In a study of 72 employed patients recruited in 1 center of the Netherlands, $12 \%$ had sick leave over a period of 2 weeks and $53 \%$ experienced an adverse influence of AS on work productivity while at work, emphasizing, as has been found in our current much larger study, the importance of considering presenteeism when assessing work impact in axSpA ${ }^{27}$. The relationship between high disease activity and work impact has previously been reported in cross-sectional studies. For example, a small study of 51 Italian patients recruited to the SPACE study showed an association with absenteeism, presenteeism, and overall work productivity, relationships also evident with poor function ${ }^{28}$. Bakland, et $a l^{29}$ recruited 360 patients, registered with AS in a single hospital in Norway, to a cross-sectional study. Work disability was related to current poor function (BASFI) and mobility (BASMI), comorbidities, as well as older age, female sex, and lower levels of education. All these data are cross-sectional, and while giving important insights, do not allow us to understand the pathways to work disability and cannot disentangle factors leading to work disability from consequences of work disability. For example, the observation that patients with rheumatoid arthritis (RA) who remain in employment have better health-related quality of life $^{30}$ could be interpreted as employment having positive

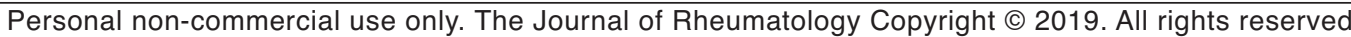


effects on quality of life or that those with higher quality of life and lower disease severity are more able to stay in employment.

A longitudinal analysis of 720 patients with axSpA in Sweden found that these factors were related to work disability 2.5 years later: poor quality of life, worse disease activity, decreased physical function, lower self-efficacy, and higher scores of anxiety, depression, and smoking, and low education $^{31}$. An important longitudinal analysis of 105 participants in the previously noted SPACE study demonstrated that improvements in disease activity were related to improvement in work productivity. Specifically, a decrease in ASDAS of 1 unit was associated with a $5 \%$ and $17 \%$ improvement in absenteeism and presenteeism, respectively ${ }^{3}$. We have previously shown within the BSRBR-AS, using propensity score matching, that biologic therapy is associated with a significantly greater improvement in presenteeism 12 months later, in comparison with patients continuing other therapies $(-14.3 \%, 95 \% \text { CI }-24.7 \text { to }-4.0)^{32}$. Similarly, in a cohort of patients with axSpA in Sweden starting anti-tumor necrosis factor inhibitor therapy, their number of sick days decreased from 3 times to 2 times that of the general population over the subsequent 2 years ${ }^{33}$. Taken together with the current results, this body of evidence is suggestive of a direct relationship between disease activity and presenteeism.

The current analysis shows an important association between high levels of fatigue and presenteeism and this has been noted in some previous studies. In the cross-sectional study of Espahbodi, et $a l^{2}$, high levels of fatigue in patients with axSpA were associated with work productivity loss and absenteeism. In RA, where fatigue has been demonstrated as an important influence on poor quality of life and employment ${ }^{34,35}$, improvement in physical function and relief from fatigue and pain have been associated with increased productivity at work among patients treated with certolizumab pegol ${ }^{36}$. However, drug therapy (including biologics) only modestly improves fatigue in $\mathrm{RA}^{37}$. Results from preliminary studies of nonpharmacological management (cognitive behavior therapy) in RA give cause for optimism (Dures, et $\mathrm{al}^{38}$ ) and randomized controlled trials are currently under way to assess the effectiveness of physical activity or cognitive behavior therapy in improving fatigue both in RA and across inflammatory rheumatic disorders ${ }^{39,40}$. Among workers, such approaches are unlikely to achieve optimal results unless they are at least partly focused on workplace issues ${ }^{41}$.

This analysis of a national disease register has shown that high disease activity, fatigue, poor function, and undertaking a physically demanding job are associated with patients reporting presenteeism at work. Presenteeism and undertaking a physically demanding job increases the risk of absenteeism, which is then associated with leaving work altogether. These results characterize workers at high risk of a poor outcome but also identify targets that could improve such outcomes. While biologic therapy targeting disease activity has been shown to bring about modest improvements in fatigue, providing nonpharmacological therapies that include specific focus on the workplace is likely to be necessary for the improvements that patients seek.

\section{ACKNOWLEDGMENT}

We are grateful to the staff of the BSRBR-AS register, who are currently Claudia Zabke, Maureen Heddle, Nafeesa Nazlee, and Barry Morris, and to the recruiting staff at the clinical centers, details of which are available from: www.abdn.ac.uk/iahs/research/epidemiology/spondyloarthritis.php\#panel1011.

\section{ONLINE SUPPLEMENT}

Supplementary material accompanies the online version of this article.

\section{REFERENCES}

1. Martindale J, Shukla R, Goodacre J. The impact of ankylosing spondylitis/axial spondyloarthritis on work productivity. Best Pract Res Clin Rheumatol 2015;29:512-23.

2. Espahbodi S, Bassett P, Cavill C, Freeth M, Hole J, Sengupta R. Fatigue contributes to work productivity impairment in patients with axial spondyloarthritis: a cross-sectional UK study. Clin Exp Rheumatol 2017;35:571-8.

3. van Lunteren M, Ez-Zaitouni Z, Fongen C, Landewé R, Ramonda $R$, van der Heijde D, et al. Disease activity decrease is associated with improvement in work productivity over 1 year in early axial spondyloarthritis (SPondyloArthritis Caught Early cohort). Rheumatology 2017;56:2222-8.

4. Brown J, Isaacs D. The world cafe: shaping our futures through conversations that matter. San Francisco: Bennett-Koehler Publishers Inc.; 2005.

5. Bevan S, Brinkley I, Cooper C, Bajorek Z. 21st century workforces and workplaces. The challenges and opportunities for future work practices and labour markets. London: Bloomsbury Business; 2018.

6. Rudwaleit M, van der Heijde D, Landewé R, Listing J, Akkoc N, Brandt J, et al. The development of Assessment of SpondyloArthritis international Society classification criteria for axial spondyloarthritis (part II): validation and final selection. Ann Rheum Dis 2009;68:777-83.

7. Macfarlane GJ, Barnish MS, Jones EA, Kay L, Keat A, Meldrum KT, et al. The British Society for Rheumatology Biologics Registers in Ankylosing Spondylitis (BSRBR-AS) study: protocol for a prospective cohort study of the long-term safety and quality of life outcomes of biologic treatment. BMC Musculoskelet Disord 2015;16:347.

8. Reilly MC, Zbrozek AS, Dukes EM. The validity and reproducibility of a work productivity and activity impairment instrument. Pharmacoeconomics 1993;4:353-65.

9. Reilly MC, Gooch KL, Wong RL, Kupper H, van der Heijde D. Validity, reliability and responsiveness of the Work Productivity and Activity Impairment Questionnaire in ankylosing spondylitis. Rheumatology 2010;49:812-9.

10. Jenkinson TR, Mallorie PA, Whitelock HC, Kennedy LG, Garrett SL, Calin A. Defining spinal mobility in ankylosing spondylitis (AS). The Bath AS Metrology Index. J Rheumatol 1994;21:1694-8.

11. Garrett S, Jenkinson T, Kennedy LG, Whitelock H, Gaisford P, Calin A. A new approach to defining disease status in ankylosing spondylitis: the Bath Ankylosing Spondylitis Disease Activity Index. J Rheumatol 1994;21:2286-91.

12. Calin A, Garrett S, Whitelock H, Kennedy LG, O’Hea J, Mallorie P, et al. A new approach to defining functional ability in ankylosing spondylitis: the development of the Bath Ankylosing Spondylitis Functional Index. J Rheumatol 1994;21:2281-5. Personal non-commercial use only. The Journal of Rheumatology Copyright (c) 2019. All rights reserved. 
13. Jones SD, Steiner A, Garrett SL, Calin A. The Bath Ankylosing Spondylitis Patient Global Score (BAS-G). Br J Rheumatol 1996;35:66-71.

14. Doward LC, Spoorenberg A, Cook SA, Whalley D, Helliwell PS, Kay LJ, et al. Development of the ASQoL: a quality of life instrument specific to ankylosing spondylitis. Ann Rheum Dis 2003;62:20-6.

15. EuroQoL Group. EuroQol: A new facility for the measurement of health-related quality of life. Health Policy 1990;16:199-208.

16. Zigmond AS, Snaith RP. The hospital anxiety and depression scale. Acta Psychiatr Scand 1983;67:361-70.

17. Chalder T, Berelowitz G, Pawlikowska T, Watts L, Wessely S, Wright D, et al. Development of a fatigue scale. J Psychosom Res 1993;37:147-53.

18. Jenkins CD, Stanton BA, Niemcryk SJ, Rose RM. A scale for the estimation of sleep problems in clinical research. J Clin Epidemiol 1988;41:313-21.

19. Ministry of Housing, Communities \& Local Government. Index of Multiple Deprivation Score, 2010. [Internet. Accessed September 26, 2018.] Available from: opendatacommunities.org/data/ societal-wellbeing/deprivation/imd-score-2010

20. Scottish Executive. Scottish Index of Multiple Deprivation 2004: Summary Technical Report. Edinburgh: Scottish Executive; 2004. [Internet. Accessed September 26, 2018.] Available from: www.gov.scot/Publications/2004/06/19429/38161

21. Liang KY, Zeger SL. Longitudinal data analysis using generalized linear models. Biometrika 1986;73:13-22.

22. Huber PJ. The behavior of maximum likelihood estimates under nonstandard conditions. In: Proceedings of the fifth Berkeley symposium on mathematical statistics and probability, volume 1: statistics. Berkeley: University of California Press; 1967;1:221-33.

23. Jones GT, Keat A, Pathan E, Macfarlane GJ. Real-world effectiveness of TNF inhibition in spondyloarthritis. Data from a large nationwide prospective cohort - the British Society for Rheumatology Biologics Register for Ankylosing Spondylitis [abstract]. Arthritis Rheumatol 2017;69 Suppl 10:1543.

24. Molto A, Tezenas du Montcel S, Wendling D, Dougados M, Vanier A, Gossec L. Disease activity trajectories in early axial spondyloarthritis: results from the DESIR cohort. Ann Rheum Dis 2017;76:1036-41.

25. Ramiro S, Landewé R, van Tubergen A, Boonen A, Stolwijk C, Dougados M, et al. Lifestyle factors may modify the effect of disease activity on radiographic progression in patients with ankylosing spondylitis: a longitudinal analysis. RMD Open 2015;1:e000153

26. Villaverde-García V, Cobo-Ibáñez T, Candelas-Rodríguez G, Seoane-Mato D, Campo-Fontecha PDD, Guerra M, et al. The effect of smoking on clinical and structural damage in patients with axial spondyloarthritis: a systematic literature review. Semin Arthritis Rheum 2017;46:569-83.

27. Boonen A, Brinkhuizen T, Landewé R, van der Heijde D, Severens JL. Impact of ankylosing spondylitis on sick leave, presenteeism and unpaid productivity, and estimation of the societal cost. Ann Rheum Dis 2010;69:1123-8.
28. de Hooge M, Ramonda R, Lorenzin M, Frallonardo P, Punzi L, Ortolan A, et al. Work productivity is associated with disease activity and functional ability in Italian patients with early axial spondyloarthritis: an observational study from the SPACE cohort. Arthritis Res Ther 2016;18:265.

29. Bakland G, Gran JT, Becker-Merok A, Nordvåg BY, Nossent JC Work disability in patients with ankylosing spondylitis in Norway. J Rheumatol 2011;38:479-84

30. Grønning K, Rødevand E, Steinsbekk A. Paid work is associated with improved health-related quality of life in patients with rheumatoid arthritis. Clin Rheumatol 2010;29:1317-22.

31. Haglund E, Petersson IF, Bremander A, Bergman S. Predictors of presenteeism and activity impairment outside work in patients with spondyloarthritis. J Occup Rehabil 2015;25:288-95.

32. Macfarlane GJ, Jones GT, Shim J. Are work outcomes improved in axial spondyloarthritis (axSpA) patients with biologic therapy? Results from the British Society for Rheumatology Register [abstract]. Arthritis Rheumatol 2017;69 Suppl 10:2500.

33. Wallman JK, Jöud A, Olofsson T, Jacobsson LT, Bliddal H, Kristensen LE. Work disability in non-radiographic axial spondyloarthritis patients before and after start of anti-TNF therapy: a population-based regional cohort study from southern Sweden. Rheumatology 2017;56:716-24.

34. Rupp I, Boshuizen HC, Jacobi CE, Dinant HJ, van den Bos GA Impact of fatigue on health-related quality of life in rheumatoid arthritis. Arthritis Care Res 2004;51:578-85.

35. de Croon EM, Sluiter JK, Nijssen TF, Kammeijer M, Dijkmans BA, Lankhorst GJ, et al. Work ability of Dutch employees with rheumatoid arthritis. Scand J Rheumatol 2005;34:277-83.

36. Hazes JM, Taylor P, Strand V, Purcaru O, Coteur G, Mease P. Physical function improvements and relief from fatigue and pain are associated with increased productivity at work and at home in rheumatoid arthritis patients treated with certolizumab pegol. Rheumatology 2010;49:1900-10.

37. Almeida C, Choy EH, Hewlett S, Kirwan JR, Cramp F, Chalder T, et al. Biologic interventions for fatigue in rheumatoid arthritis. Cochrane Database Syst Rev 2016;6:CD008334.

38. Dures E, Kitchen K, Almeida C, Ambler N, Cliss A, Hammond A, et al. "They didn't tell us, they made us work it out ourselves": patient perspectives of a cognitive-behavioral program for rheumatoid arthritis fatigue. Arthritis Care Res 2012;64:494-501.

39. Hewlett S, Ambler N, Almeida C, Blair PS, Choy E, Dures E, et al; RAFT Study Team. Protocol for a randomised controlled trial for Reducing Arthritis Fatigue by clinical Teams (RAFT) using cognitive-behavioural approaches. BMJ Open 2015;5:e009061.

40. Arthritis Research UK. Lessening the impact of fatigue: therapies for inflammatory rheumatic diseases (LIFT). [Internet. Accessed September 26, 2018.] Available from: www.arthritisresearchuk.org/ research/grant-tracker-items/2016/lessening-the-impact-of-fatiguetherapies-for-inflammatory-rheumatic-diseases-lift.aspx

41. Allaire SH, Li W, LaValley MP. Reduction of job loss in persons with rheumatic diseases receiving vocational rehabilitation: a randomized controlled trial. Arthritis Rheum 2003;48:3212-8. 


\section{Correction}

\section{Identifying Persons with Axial Spondyloarthritis At Risk of Poor Work Outcome: Results from the British Society for Rheumatology Biologics Register}

Macfarlane GJ, Shim J, Jones GT, Walker-Bone K, Pathan E, Dean LE. Identifying persons with axial spondyloarthritis at risk of poor work outcome: results from the British Society for Rheumatology Biologics Register. J Rheumatol 2019; doi:10.3899/jrheum.180477. In the Results section of the text, first paragraph, the fourth sentence should read: "A higher proportion of those not working fulfilled only the ASAS clinical criteria, compared to those working (15\% vs 7\%)." The type of criteria involved was incorrect. A corrected Table 1 from the article follows below.

doi:10.3899/jrheum.180477.C1

Table 1. Baseline characteristics of the BSRBR-AS population.

\begin{tabular}{lcc}
\hline Characteristics & $\begin{array}{c}\text { Working, } \\
\mathrm{n}=1188\end{array}$ & $\begin{array}{c}\text { Not Working, } \\
\mathrm{n}=733\end{array}$ \\
\hline Age, yrs ** & $43.7(34.6-52.3)$ & $62.2(48.1-68.3)$ \\
Age at rheumatology referral, yrs ** & $33(26-42)$ & $41(29-52)$ \\
Sex, male* & $767(65)$ & $529(72)$ \\
Classification criteria** & & \\
Modified New York criteria & $635(53)$ & $237(32)$ \\
ASAS imaging & $475(40)$ & $383(52)$ \\
ASAS clinical & $78(7)$ & $113(15)$ \\
HLA-B27 status** & & \\
Positive & $684(83)$ & $337(75)$ \\
Negative & $145(17)$ & $115(25)$ \\
Job type & & \\
Sedentary & $715(55)$ & - \\
Labor-intensive & $592(45)$ & - \\
Absenteeism, \% & $0(0-0)$ & - \\
Presenteeism, \% & $30(10-50)$ & - \\
Overall work impairment, \% & $30(10-53)$ & - \\
Activity impairment (\%)** & $30(10-60)$ & $60(30-80)$ \\
& Logistic Regression \\
Likelihood of working** & OR & $95 \%$ CI \\
BASDAI (scored: 0 best-10 worst) & 0.74 & $0.70-0.79$ \\
BASFI (scored: 0 best-10 worst) & 0.70 & $0.66-0.73$ \\
BASMI (scored: 0 best-10 worst) & 0.69 & $0.64-0.75$ \\
ASQoL (scored: 0 best-18 poorest) & 0.84 & $0.81-0.86$ \\
& &
\end{tabular}

Values are $\mathrm{n}(\%)$ or median (IQR) unless otherwise indicated. * Statistically significant difference between work and not working of $\mathrm{p}<0.05$. ** Statistically significant difference between work and not working of $\mathrm{p}<$ $0.01 .^{\dagger}$ Adjusted for age, sex, and deprivation. BSRBR-AS: British Society for Rheumatology Biologics Register in Ankylosing Spondylitis; ASAS: Assessment of Spondyloarthritis international Society; BASDAI: Bath Ankylosing Spondylitis Disease Activity Index; BASFI: Bath AS Functional Index; BASMI: Bath AS Metrology Index; ASQoL: Ankylosing Spondylitis Quality of Life questionnaire; IQR: interquartile range. 


\section{A Rose by Any Other Name: Classified Accelerated Erosive Osteoarthritis or Calcium Pyrophosphate Deposition Disease, a Clarion for Aggressive Intervention}

To the Editor:

The analysis of accelerated osteoarthritis (OA) by Davis, et $a l^{1}$ noted the predominantly interphalangeal joint distribution of associated erosions and suggested a likely inflammatory derivation of the process. That description, however, is also applicable to a disorder long recognized as inflammatory in character: calcium pyrophosphate deposition disease (CPPD) ${ }^{2}$.

Several studies document the development of destructive arthropathy in $\mathrm{CPPD}^{3,4,5}$ and the association of distal and proximal interphalangeal joint erosions with other manifestations of $\mathrm{CPPD}^{6,7}$. Such correlation does not assure causality, but does direct consideration of therapeutic intervention. Hydroxychloroquine has not proven effective in treatment of $\mathrm{OA}^{8}$, but has documented efficacy in $\mathrm{CPPD}^{9}$, especially protecting the small joints of the hand. What has been referred to as erosions of those joints has a unique appearance. Rather than the sharply defined erosions characteristic of rheumatoid arthritis and spondyloarthropathy, high magnification views of articular surfaces reveal that the erosions of CPPD have smudged edges suggesting a crumbling rather than an "excised" derivation ${ }^{10}$. Davis, et al have expanded the spectrum of what has been referred to as erosive OA, suggesting that it represents a unique phenotype ${ }^{1}$. The destructive phenomenon to which they refer, independent of its labeling/classification as erosive OA or as CPPD, appears significantly more responsive to medical intervention than does nonerosive, nondestructive OA. Thus, its recognition should stimulate more aggressive intervention than that limited to the nonsteroidal antiinflammatory drugs that have been standard treatment for OA.

BRUCE M. ROTHSCHILD (D), MD, Indiana University School of Medicine, Muncie, Indiana, USA. Address correspondence to Dr. B.M. Rothschild, 2401 W. University Ave., Muncie, Indiana 47303, USA.

E-mail: spondylair@gmail.com

\section{REFERENCES}

1. Davis JE, Schaefer LF, McAlindon TE, Eaton CB, Roberts MB, Haugen IK, et al. Characteristics of accelerated hand osteoarthritis: data from the osteoarthritis initiative. J Rheumatol 2019;46:422-8.

2. Rothschild BM, Woods RJ, Rothschild C. Calcium pyrophosphate deposition disease: description in defleshed skeletons. Clin Exp Rheumatol 1992;10:557-64.

3. Gerster JC, Vischer TL, Fallet GH. Destructive arthropathy in generalized osteoarthritis with articular chondrocalcinosis. J Rheumatol 1975;2:265-9.

4. Richards AJ, Hamilton EB. Destructive arthropathy in chondrocalcinosis articularis. Ann Rheumatic Dis 1974;33:196-203.

5. Villiaumey J, Larget-Piet B, Menza CD, Rotterdam M. [Symptomatic and evolutive characteristics of articular destruction noted in chondrocalcinosis]. [Article in French] Rev Rhum Mal Osteoartic 1975;42:263-73.

6. Shah EN, Reddy N, Rothschild BM. Fractal analysis of acceleration signals from patients with CPPD, rheumatoid arthritis and spondyloarthropathy of the finger joint. Comput Methods Programs Biomed 2005;77:233-9.

7. McCarthy DJ. Diagnostic mimicry in arthritis patterns of joint involvement associated with calcium pyrophosphate dehydrate crystal deposits. Bull Rheumatic Dis 1975;25:804-9.

8. Lee W, Ruijgrok L, Boxma-de Klerk B, Kok MR, Kloppenburg M, Gerards A, et al. Efficacy of hydroxychloroquine in hand osteoarthritis: a randomized, double-blind, placebo-controlled trial. Arthritis Care Res 2018;70:1320-5.

9. Rothschild BM. Prospective six month, double-blind trial of hydroxychloroquine treatment of CPPD. Comp Ther 1997; 23:327-31.

10. Rothschild BM. Differential diagnostic perspectives provided by en face microscopic examination of articular surface defects. Clin Rheumatol 2018;31:831-6.

First Release June 1 2019; J Rheumatol 2019;46:7;

doi:10.3899/jrheum.190464 